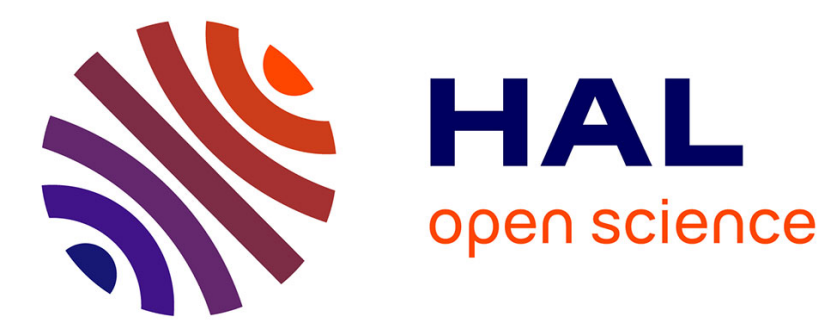

\title{
Pseudo bond graph model of a thermo-hydraulic system
}

Emna Aridhi, Mehdi Abbes, Abdelkader Mami

\section{To cite this version:}

Emna Aridhi, Mehdi Abbes, Abdelkader Mami. Pseudo bond graph model of a thermo-hydraulic system. International Conference on Modeling, Simulation and Applied Optimization, Apr 2013, Tunis, Tunisia. 10.1109/ICMSAO.2013.6552551 . hal-01122778

\section{HAL Id: hal-01122778 https://hal.science/hal-01122778}

Submitted on 4 Mar 2015

HAL is a multi-disciplinary open access archive for the deposit and dissemination of scientific research documents, whether they are published or not. The documents may come from teaching and research institutions in France or abroad, or from public or private research centers.
L'archive ouverte pluridisciplinaire HAL, est destinée au dépôt et à la diffusion de documents scientifiques de niveau recherche, publiés ou non, émanant des établissements d'enseignement et de recherche français ou étrangers, des laboratoires publics ou privés. 


\title{
Pseudo Bond graph Model of a Thermo-Hydraulic System
}

\author{
Emna Aridhi ${ }^{(1)}$, Mehdi Abbes ${ }^{(2)}$, Abdelkader Mami ${ }^{(1)}$ \\ (1) Tunis El Manar University, Faculty of Sciences of Tunis \\ (2) Tunis El Manar University, National School of Engineering of Tunis \\ LACCS Laboratory of Analyze, Conception and Control of Systems, Team: Modelisation and Control of renewable Energies \\ Systems, 2092, Tunis, Tunisia \\ Email: aridhi_emna@yahoo.fr, mehdi.abbes@enit.rnu.tn, abdelkader.mami@fst.rnu.tn
}

\begin{abstract}
The paper presents a pseudo bond graph model of a thermo-hydraulic system which is composed by two warm and cold water pipes, a plastic tank and an evacuation pipe. This model is designed on 20sim software and it allows varying the temperature, inside the tank, by acting on the mass flows of the warm and cold water, as well as on the evacuation pipe. A simulation is done for constant and variable water mass flows to show the efficiency of this bond graph model.
\end{abstract}

Keywords-Bond graph; Thermal transfer; Hydraulic transfer; Hydraulic thermal coupling; Modeling.

\section{INTRODUCTION}

The energy systems, characterized by interaction between several physical phenomena such as thermal and hydraulic transfers, have a complex dynamic behavior and a nonlinear aspect. Therefore, it is delicate to model and to control them.

The bond graph formalism presents an easy and a simple graphical method for the modeling of these physical processes and multidisciplinary dynamic engineering systems. They include efforts, flows, integrate components and sensors from different energy domains (thermal, hydraulic, mechanical, electrical, chemical...) [1,3].

This approach allows satisfying the basic principles of physics, such as energy conservation, power continuity.... It also permits the modeling of the power transfers inside the system, the coupling between thermo-hydraulic variables, the dissipation and the storage phenomena. Then, it is possible to extract constitutive relations and dynamic equations from the bond graph model between its sources and its different elements according to the causality and the direction of the energy distribution.

Several worldwide studies were interested in the bond graph modeling of these energy systems $[10,12,13]$, almost in thermal, hydraulic and chemical domains. There are bond graphs modeling of a hydraulic system such as pipes with valves connected to a tank [2], a thermo-hydraulic system such as a thermal tank $[2,4,9]$. Multi ports are used to model the coupling between the thermal and hydraulic variables $[5,6,7]$.

The bond graph modeling of the system inspires of these works. Indeed, there is presence of warm and cold water pipes which are equipped by valves and a tank as well as an evacuation pipe. The power variables, used in the model, are 978-1-4673-5814-9/13/\$31.00 the hydraulic couple (Pressure and mass flow) and the thermal couple (Temperature and heat flow for transfer by conduction and enthalpy flow for transfer by convection inside the tank) $[9,12]$.

In this paper, we present a pseudo bond graph model of a thermo-hydraulic system. It illustrates the pseudo-thermal and pseudo-hydraulic transfers through bonds, the flow sources, the hydraulic and thermal energy dissipation respectively at the valves level and the tank's walls, the coupling and the storage energy processes. For the simulation of the model, it is possible to vary the mass flows and also the temperature of the cold water and the warm water to vary the water temperature inside the tank.

The paper is structured as follows: in Section II, we describe the thermo-hydraulic system; we explain the physical phenomena which interact inside and its correspondent word bond graph model. Section III presents the pseudo bond graph model and the dynamic equations. Section VI illustrates the simulation results. The last section is devoted to conclude this paper.

\section{THE THERMO-HYDRAULIC SYSTEM}

The thermo-hydraulic system, to be modeled in bond graph, is illustrated by Fig. 1.

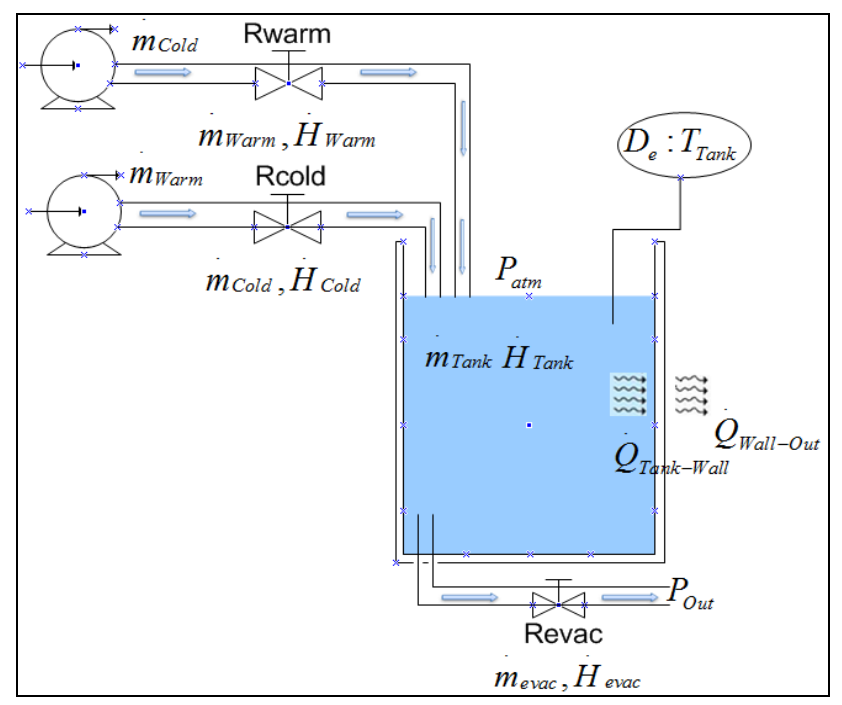

Figure 1. Synoptic scheme of the thermo-hydraulic system. 
It is constituted by two warm and cold water pipes, debiting two water quantities in the tank, which are moderated by the valves. As well as an evacuation pipe that prevents the complete filling of the tank and maintains a constant water level.

The quantities of warm and cold water injected in the tank are modeled by two flow sources (mass flows) of which are determined the correspondent heat flows.

Every valve presents a hydraulic resistance. Furthermore, there will be a thermal dissipation at the walls level of the pipes and the tank. In fact, the heat, inside it, is transferred by convection which is presented by the enthalpy flow and also by conduction which is presented by the heat flow, under the influence of the outside temperature.

\section{A. The involved physical phenomena}

The dynamic behavior of the system is essentially described by the interaction between the hydraulic and thermal phenomena during the mixture between the warm and cold water. Indeed, it is characterized by a coupling of the hydraulic and thermal variables.

The water, in flow, undergoes a pressure drop and a hydraulic dissipation at the pipes valves level, caused by the water friction. The water quantity, in constant pressure, debited from the two pipes and injected in the tank, allows to transport a heat quantity which will be stored by water molecules or be dissipated by conduction in heat form (the tank is supposed not heat-insulated) or stored at the level of the tank's walls. This transfer is influenced by the outside temperature (of the air). The warm and cold water's mass flows are evacuated, in a big part, by the evacuation pipe.

\section{B. Word bond graph model}

The word bond graph model is presented in Fig. 2.

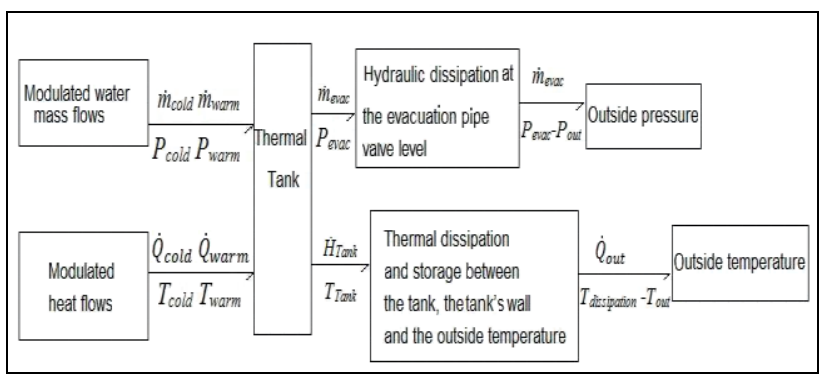

Figure 2. Word bond graph model of the thermo-hydraulic system.

The warm and cold water pipes are presented by two modulated mass flow sources. The heat flow sources are modulated by the temperature of the warm and cold water and the two pipes mass flows. The heat quantity in the tank is transferred by convection. Thus, it is stored in heat energy form and also dissipated at the level of the tank's walls under the effect of the outside temperature.

At the valves level, there is a hydraulic dissipation due to the water friction.

\section{Hypothesis}

For the bond graph modeling of the thermo-hydraulic system, we suppose that the outside temperature is equal to $20^{\circ} \mathrm{C}$, the initial water temperature inside the tank is $42.93^{\circ} \mathrm{C}$ and the outside pressure is equal to zero.

\section{PSEUDO BOND GRAPH MODEL OF THE THERMO- HYDRAULIC SYSTEM}

\section{A. Pseudo Bond graph Model}

The pseudo bond graph model is designed on 20sim software. It is shown in Fig. 3.

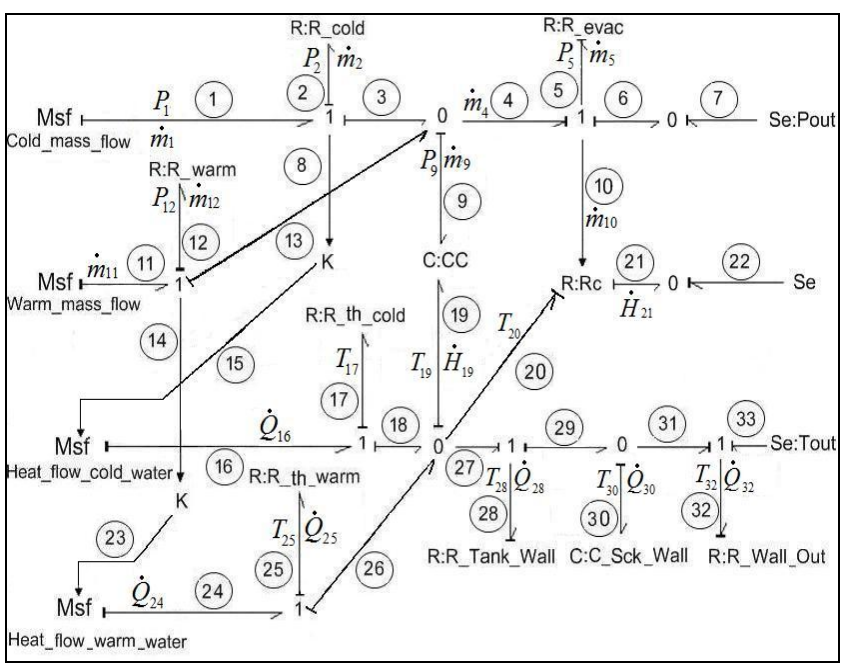

Figure 3. Pseudo bond graph model of the thermo-hydraulic system.

The model is constituted by a hydraulic part and a thermal part:

- The hydraulic effort- flow couple, used in this model, is the pressure and the mass flow and not the volume flow (the water is assumed incompressible, so the water density is neglected).

- The two pipes debit a warm and cold mass flows which are presented by two modulated flow sources (Msf: Cold_mass_flow and Msf:Warm_mass_flow). At each valve level, the hydraulic dissipation is modeled by simple R element: R_cold for the cold pipe valve, $\mathrm{R}$ _warm for the warm pipe valve and $\mathrm{R}$ _evac for the evacuation pipe valve.

- The thermal effort-flow couple is the temperature and the heat flow $\dot{Q}_{27}$ for conduction transfer and the enthalpy flow $\dot{\mathrm{H}}_{19}$ for the convection transfer.

- The thermal dissipation at the pipes walls level is modeled by two simple $\mathrm{R}$ elements ( $\mathrm{R}$ _th_cold and R_th_warm).

- $\quad$ The thermal energy storage in the tank is modeled by a multiport $\mathrm{C}: \mathrm{CC}$ which highlights the coupling between the temperature and mass of the water inside the tank.

- At the level of the tank's walls, the heat dissipation (transferred by conduction) is modeled by two simple 
R elements: R_Tank_Wall for the exchange between the tank and the walls and R_Wall_Out for the exchange between the walls and the outside. The thermal energy storage is modeled by a simple $\mathrm{C}$ element (C_Sck_Wall).

- At the evacuation pipe level, the heat flow is modeled by a multiport R:Rc.

\section{B. Dynamic equations deducted from the bond graph model}

- For the hydraulic dissipation in the pipes and modeled by the simple $\mathrm{R}$ elements, the pressures $\mathrm{P}_{2}$ and $\mathrm{P}_{12}(\mathrm{~Pa})$ are computed in (1) according to the Bernoulli law [9].

$$
\begin{aligned}
& P_{2}=R_{\text {_cold }} * \dot{m}_{2}^{2} \\
& P_{12}=R_{\text {_warm }} * \dot{m}_{12}^{2}
\end{aligned}
$$

With R_cold and R_warm are the debit coefficients.

- The hydraulic capacity's equation is given by (2) [2].

$$
P_{9}=\frac{m_{9}}{C_{h}}
$$

With $C_{h}=\frac{A}{g}$, where A is the tank section $\left(\mathrm{m}^{2}\right)$ and $\mathrm{g}$ is the constant of gravity: $g=9.81 \mathrm{~m} / \mathrm{s}^{2} . \mathrm{C}_{\mathrm{h}}$ is expressed in m.s. $\mathbf{s}^{2}$.

$\mathrm{P}_{9}$ is the pressure and $\mathrm{m}_{9}$ is the water mass inside the tank:

$$
m_{9}=m_{\text {inital }}+\int \dot{m}_{9} d t(\mathrm{~kg}) \cdot \dot{m}_{9} \text { is expressed in } \mathrm{Kg} / \mathrm{s} \text {. }
$$

- The outlet hydraulic resistance's equation is (3) [9].

$$
\dot{m}_{5}=\left(1 / R_{\text {evac }}\right) * \operatorname{sign}\left(P_{5}\right) * \sqrt{\left|P_{5}\right|}
$$

- The equation of the thermal resistance due to the dissipation at the walls level for every water pipe is (4) [2].

$$
\begin{aligned}
& T_{17}=R_{-}{ }^{\text {th }}{ }_{-} \text {cold }^{*} \dot{Q}_{17} \\
& T_{25}=R_{\text {_th }}{ }_{\text {twarm }} * \dot{Q}_{25}
\end{aligned}
$$

- The thermal capacity's equation is $(5)[2,12]$.

$$
T_{19}=T_{\text {initial }}+\frac{H_{19}}{C_{t h}}
$$

With $C_{t h}=C_{V} * m_{9}$ [2], where $\mathrm{C}_{\mathrm{V}}$ is the water thermal specific capacity in constant volume $\left(\mathrm{C}_{\mathrm{V}}=4185 \mathrm{~J} / \mathrm{Kg} . \mathrm{K}\right)$.

$\mathrm{T}_{19}$ is expressed in Kelvin, $\mathrm{C}_{\mathrm{th}}$ is expressed in $\mathrm{J} / \mathrm{K}$ and $\mathrm{H}_{19}$ is expressed in Joules where $H_{19}=\int \dot{H}_{19} d t$.
- At the level of the tank's wall, the equation of outlet thermal resistances between (tank, wall) and (wall, outside) is (6) [2].

$$
\begin{aligned}
& \dot{Q}_{28}=\frac{T_{28}}{R_{-} \text {Tank_Wall }} \\
& \dot{Q}_{32}=\frac{T_{32}}{R_{\text {_Tank_Out }} \text { Tant }}
\end{aligned}
$$

With:

$$
R_{-} \text {Tank_Wall }=R_{-} \text {Tank_Out }=\frac{e}{\lambda * S}
$$

where e is the tank thickness $(\mathrm{m}), \lambda$ is the plastic thermal conductivity $(\mathrm{W} / \mathrm{m} \cdot \mathrm{K})$ and $\mathrm{S}$ is the exchange surface $\left(\mathrm{m}^{2}\right)$. The outlet thermal resistances are expressed in $\mathrm{K} / \mathrm{W}$ and the heat flows $\dot{Q}_{28}$ and $\dot{Q}_{32}$ are expressed in $\mathrm{J} / \mathrm{s}$.

- At the level of the tank's walls, the thermal storage capacity's equation is the (7) $[2,9,12]$.

$$
T_{30}=\frac{Q_{30}}{C_{-} S c k \_ \text {Wall }}
$$

With:

$C_{\_} S c k \_W a l l=C_{\text {th_plastic }} * \rho_{\text {plastic }} * V[2]$, where

$C_{\text {th_plastic }}$ is the plastic thermal specific capacity:

$C_{\text {th_plastic }}=3200 \mathrm{~J} / \mathrm{Kg} . \mathrm{K}$.

$\rho_{\text {plastic }}$ is the plastic density: $\rho_{\text {plastic }}=(1.17)^{3} \mathrm{~kg} / \mathrm{m}^{3}$.

$\mathrm{V}$ is the wall's volume $\left(\mathrm{m}^{3}\right)$.

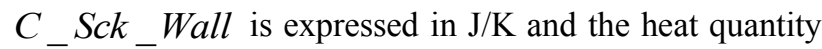

$Q_{30}$ is expressed in J: $Q_{30}=\int \dot{Q}_{30} d t$.

- The outlet multiport Rc highlights the coupling between thermo-hydraulic variables. Indeed, the enthalpy flow is computed through the temperature and the mass flow, according to (8) [2].

$$
\dot{H}_{21}=C_{p} * \dot{m}_{10} * T_{20}
$$

\section{SimULATIONS}

For simulation, we choose constant values of water mass flows as follow:

$$
\dot{\mathrm{m}}_{1}=\dot{\mathrm{m}}_{11}=0.5 \mathrm{Kg} / \mathrm{s} \text {. }
$$

The temperatures of the warm and cold water are respectively equal to $50^{\circ} \mathrm{C}$ and $10^{\circ} \mathrm{C}$. The simulation results are illustrated by Fig. 4. 


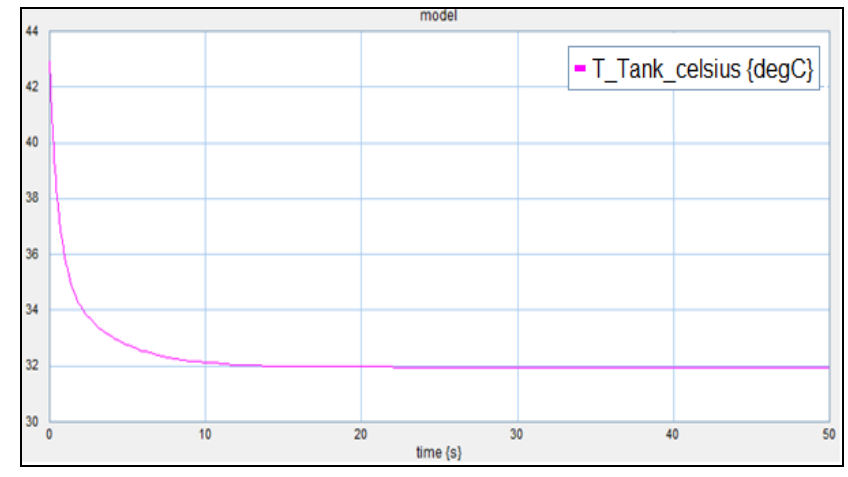

Figure 4. Pseudo bond graph model simulation result (Water temperature value inside the tank) for constant mass flows values.

The Fig. 5 illustrates the influence of the cold water's mass flow source, in the entry, on the temperature inside the tank, for $\dot{\mathrm{m}}_{11}=0.5 \mathrm{Kg} / \mathrm{s}$.

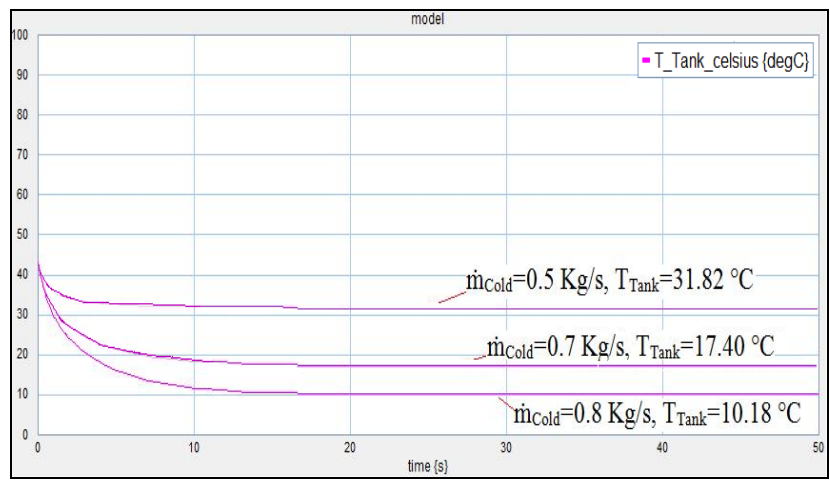

Figure 5. Influence of the cold water's mass flow on the water temperature in the tank.

The increase of the cold water's quantity, injected in the tank, allows to decrease the water temperature inside.

By gradually increasing the temperature of the warm water for a temperature of the cold water equal to $20^{\circ} \mathrm{C}$ and constant values mass flows equal to $0.5 \mathrm{Kg} / \mathrm{s}$, the water temperature in the tank increases. This is illustrated by the Fig. 6 .

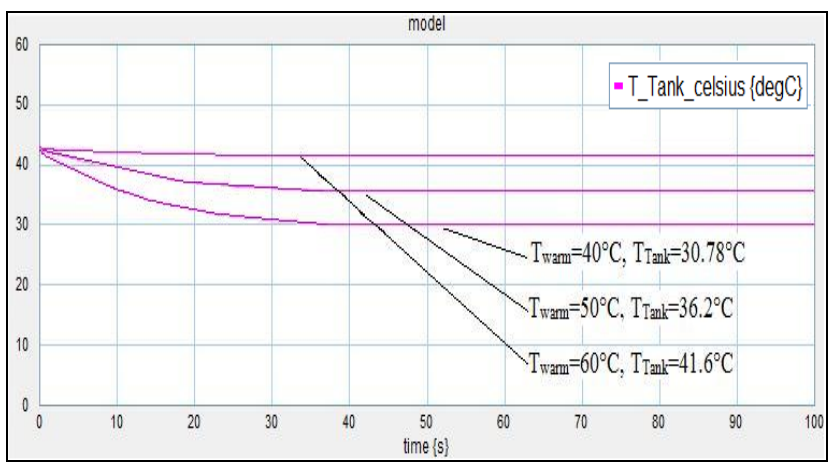

Figure 6. Influence of the warm water's temperature on the water temperature inside the tank.
For variable mass flows taken as signals of cosine and sine which the amplitude varies between 0 and $1 \mathrm{Kg} / \mathrm{s}$ and the pulsation value is fixed to $0.05 \mathrm{rad} / \mathrm{s}$, we obtain the folowing results shown in Fig. 7.

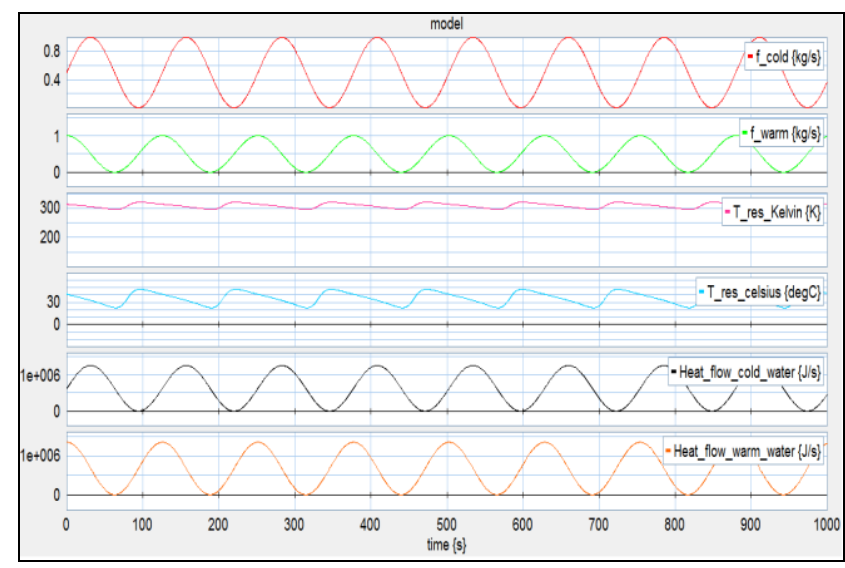

Figure 7. Simulation results of the bond graph model for variable mass flows.

We notice that the temperature value varies sinusoidally between $22.64^{\circ} \mathrm{C}$ and $47.7^{\circ} \mathrm{C}$, according to the mass flow variation of the warm and cold water.

The heat flow of the warm water varies at the rate of its mass flow between $49 \mathrm{~J} / \mathrm{s}$ and $1.35 \mathrm{MJ} / \mathrm{s}$. Also, the heat flow of the cold water varies according to the mass flow between $7.89 \mathrm{~J} / \mathrm{s}$ and $460.18 \mathrm{KJ} / \mathrm{s}$, for a temperature of the cold water equal to $20^{\circ} \mathrm{C}$ and a temperature of the warm water equal to $50^{\circ} \mathrm{C}$

An enlarged part of the previous curves shows a logical variation of the water temperature in the tank according to the mass flow of the warm and cold water. Indeed, the temperature increases when the quantity of the cold water decreases or/and the quantity of the warm water increases and in inverse case, the temperature falls. These results are illustrated by the Fig. 8 .

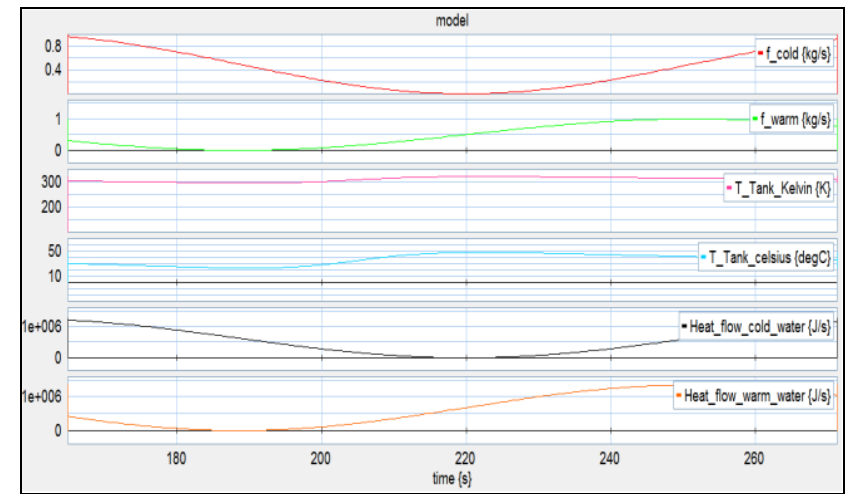

Figure 8. Water temperature variation inside the tank according to the variable water mass flows. 


\section{CONCLUSION}

A pseudo bond graph model of a thermo-hydraulic system is realized through the $20 \operatorname{sim}$ software. The thermal and hydraulic transfers are highlighted. As well as, the coupling, the hydraulic dissipation at the valves level and the thermal dissipation at the walls level of the tank and pipes.

The simulation shows the variation of the temperature in the tank according to the mass flow of the warm and cold water and their temperatures for constant and variable values in order to prove the efficiency of the bond graph model.

In future works, we plan to introduce a not linear regulator into the control loop to insure the set point tracking of the water temperature inside the tank.

\section{REFERENCES}

[1] J.L. Baliñ, A.E. Larreteguy, E.F. Gandolfo Raso, "A general bond graph approach for computational fluid dynamics". Universidade de São Paulo, Av. Prof. Mello Moraes, 2231, CEP 05508-900 Cidade Universita' ria, Sa o Paulo, SP, Brazil, Universidad Argentina de la Empresa, Lima 717, 1073 Buenos Aires, Argentina, Universidad Nacional de Cuyo, Ciudad Universitaria, Parque Gral, San Martı'n, 5500 Mendoza, Argentina. Simulation Modelling Practice and Theory $14, \mathrm{p}$. 884-908, 2006.

[2] W. Borutzky, Bond Graph Methodology Development and Analysis of Multidisciplinary Dynamic System Models. Bonn-Rhein-Sieg Universty of applied Sciences. Springer-Verlag London 2010.

[3] P. Breedveld, "Bond Graphs", Encyclopedia Life Support Systems contribution-preliminary version, Knowledge Foundation Area, Theme
Control Systems, Robotics and Automation, Topic Modeling and Simulation, University of Twente, Bertinoro, Netherlands, p. 1-27, 2003.

[4] F. T. Brown, Bond Graph Modeling and Simulation of Thermodynamic Systems. Lehigh University, emeritus, Bethlehem, PA. Present address: 1983 Sunderland Drive, Bethlehem, PA 18015, 2007.

[5] F. Busson, "Les bond graphs multiénergies pour la modélisation et la surveillance en génie des procédés", Thesis, Université des Sciences et Technologies de Lille. Laboratoire d'Automatique et d'Informatique Industrielle de Lille, 2002.

[6] W. El Osta, "Surveillabilité structurelle et platitude pour le diagnostic des modèles Bond Graph couplés", Thesis, Université des Sciences et Technologies de Lille. Laboratoire d'Automatique, Génie Informatique et Signal LAGIS - UMR CNRS 8146, 2005.

[7] P. Fichoul, "Bond graphs : une méthode pluridisciplinaire", p. 37-46, 2004.

[8] P. J. Gawthrop, "Thermal modelling using mixed energy and pseudo bond graphs". Proceedings of the Institution of Mechanical Engineers, Part I: Journal of Systems and Control Engineering, p. 201- 215, 1999.

[9] B. Ould Bouamama, A.K. Samantaray, Model-based Process Supervision. A Bond Graph Approach. Springer Verlag, published on 2008, Berlin, 2006.

[10] B. Ould Bouamama, G. Dauphin-Tanguy, "Modélisation par Bond Graph. Eléments de Base pour l'énergétique". Techniques de l'Ingénieurs, pages 16. BE8280, 2012.

[11] J. U Thoma, Thermofluid Systems by Multi-bondgraphs. The Franklin Institute. Department of Mechanical Engineering, University of Waterloo, Ontario, N2L 3G1, Canada, and Thoma Consulting, CH-6300 Zug, Switzerland, p. 1000-1009, 1992.

[12] J. U Thoma, B. Ould Bouamama, Modelling and Simulation in Thermal and Chemical Engineering. Bond Graph Approach. Springer Verlag, 2000 .

[13] M. Vergé, D. Jaume, Modélisation structurée des systèmes avec les Bond Graphs, Technip, 2004. 